WORKING PAPER · NO. 2020-116

COVID-19 Lockdown Policies at the State and Local Level

Austan Goolsbee, Nicole Bei Luo, Roxanne Nesbitt, and Chad Syverson AUGUST 2020

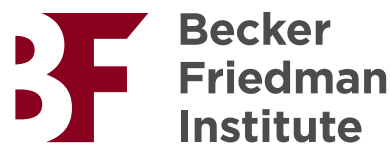




\title{
COVID-19 Lockdown Policies at the State and Local Level
}

\author{
Austan Goolsbee, Nicole Bei Luo, Roxanne Nesbitt, and Chad Syverson ${ }^{1}$ \\ Initial Draft: July 5, 2020 \\ Current Draft: August 20, 2020
}

\begin{abstract}
This paper describes a new publicly available dataset on shutdown orders and related policies at the county and city level across the United States during the early part of the COVID-19 crisis, from March through May of 2020. In hundreds of counties around the country, local governments issued sheltering orders before their state did. Larger counties and counties with higher incidence of the disease and lower GOP vote shares were more likely to enact early sheltering policies. Basic analysis of the economic impact of the orders indicates that the county-level information is important and substantially more accurate than using state-level information alone.
\end{abstract}

${ }^{1}$ Goolsbee: University of Chicago Booth School of Business, Luo: University of Chicago Booth School of Business, Nesbitt: Yale University, Syverson: University of Chicago Booth School of Business 
This note describes a new dataset on local COVID sheltering and shutdown orders and related policies at the county and city level. We compiled the data from local government sources for the early pandemic period spanning March 1 to May 16, 2020, and it was a key input in the analysis of the economic impact of the orders in Goolsbee and Syverson (2020). We believe local policy data offers a more accurate view of COVID response than state-level data. For example, we show that it significantly improves the explanatory power policy on important economic outcomes. For this reason we are making the local data available to any researchers on the Becker Friedman Institute (BFI) website, at https://bfi.uchicago.edu/working-paper/2020-116/. Researchers may use the data with no fee or permission needed. Please cite this paper as the reference.

In this note, we show that these local policies were prevalent and their timing differed from the more widely used state-level policies. Locations that adopted policies before their state did tend to be larger, have higher COVID caseloads, and a smaller GOP vote share in 2016.

\section{Constructing Local Policy Data}

The dataset identifies local shelter-in-place (SIP), non-essential business closure, and restaurant/bar closure orders when they differ from statewide policies in the locality's respective states. The data include information on 3143 counties across the U.S. through May 16, 2020. Table 1 provides an example of the data layout.

We collected these data on local sheltering orders from three separate searches. The first covered state government and health department websites to find orders imposed at the state level but directed towards specific counties. The second involved a county-by-county check of county government websites, health department websites, and local news coverage. The third crossreferenced local news sources with other databases that collected county policy data. We provide 
links to the orders for each county in the dataset and include the local news coverage in the notes column. $^{2}$

There were very few discrepancies between the county-by-county search and the crossreference check. Wherever dates disagreed, we took the date from the original order announcement. If we could not find the original order on a county associated website but another database or local news source provided the original order, we included the link to that page. In a small number of cases, a local news source mentioned an order, but we could not find the original order or governmental press release. We do not record those in the data. In several cases, no county-wide order came up in the searches, but a major city within the county issuing a city-level order did. We include all such cases we could find as documented in the notes. Sometimes the New York Times state level data would reference cities having separate orders in which case we searched the major cities of the state to find those orders directly.

We include only written orders—we do not count verbal announcements or suggestions without written orders — and recorded dates reflect the day the policy went into effect, not the day of its issuance or announcement. ${ }^{3}$ We include information on local orders implemented after statewide orders even though the statewide order, presumably, meant the local order was moot. In terms of release of such orders, the data list the date of reopening only if the local order expired after the statewide order and superseded the state reopening order. If a local restriction was not extended past the statewide order, we assume that location was still subject to the statewide order.

\footnotetext{
2 In the rapidly expanding literature on COVID, we believe our data are similar to that used in Alexander and Karger (2020), Brzezinski et al. (2020) and Gupta et al. (2020). The latter two papers use county level information from the National Association of Counties. As a result, their data do not include major city sheltering orders that we found in several major locations. We also found the NACO data sometimes classified sheltering orders as mandatory that were not announced that way. Alexander and Karger (2020) directly collected their data and do include some city-level information so are probably quite similar. However, we do not have access to that dataset to be able to cross-check in the way we can with the NACO sample.

${ }^{3}$ We report the first date the order is in effect, even if it is only part of the day. For example, if an order took effect at 11:59 PM on March 27, we would record this as being March 27.
} 
Blank cells in the data indicate no known county-level or city-level restrictions other than the relevant state regulation. We did not include closure orders on public facilities, government agencies, or nonprofits.

For state-level policy information, we use the data in the New York Times (Lee et al., 2020) as well as the information on essential businesses, restaurants, and other industries in Raifa et al. (2020). We also referenced the original state orders listed on state websites. We include the links to original state orders in the notes section.

The data include only mandatory SIP orders. We categorize a SIP order as 'mandatory' if the governing body ordered all residents to remain in their place of residence unless performing essential activities. ${ }^{4}$ The dataset does not include curfews or tailored SIP orders directed at specific populations (e.g. vulnerable citizens or visitors from hard hit locations). For a number of places, we found local governments that issued voluntary SIP orders or recommendations. Rather than include a separate variable for non-mandatory orders, we simply include these in the notes section.

We define non-essential business closure orders as those requiring businesses in multiple industries to cease operations (or, in some cases, delineated the industries that could remain open). Some orders refer to the definition of essential/critical businesses outlined by the Department of Homeland Security ${ }^{5}$ or by the state government. A few counties ordered specific industries to close before closing all non-essential businesses. In these cases, the dataset specifies when each industry closed. ${ }^{6}$ Some SIP orders required residents to stay at home except for visiting or operating essential

\footnotetext{
${ }^{4}$ Some local governments issued orders that prohibited gatherings of any size or limited public gatherings only to household members. Although local officials sometimes called such orders "effective SIP orders," we do not classify these orders as sheltering orders in our data. We take note of such orders in the notes section.

${ }^{5}$ https://www.cisa.gov/publication/guidance-essential-critical-infrastructure-workforce

${ }^{6}$ For purposes of the analysis in Section 3 below or in Goolsbee and Syverson (2020), "Close-contact" or "personal services" includes salons, barber shops, and tattoo parlors, and similar businesses, unless otherwise specified.

"Recreation," "entertainment," or "amusement" includes arcades, bowling alleys, movie theaters, amusement parks, casinos and similar businesses, unless otherwise specified. Lastly, "non-essential retail" includes clothing stores, but does not include home improvement stores, stores that sell home office supplies, and food supply stores.
} 
businesses but do not explicitly order the cessation of non-essential business operations. We do classify these orders as non-essential business closure orders if they contain a list of essential businesses unless the orders stated that they do not require any business to close.

While most non-essential business closures included dine-in services at restaurants and bars, many counties issued separate orders that specifically closed restaurants before other non-essential businesses. Restaurant closure dates in the data reflect the day the county prohibited dine-in service at restaurants, bars, taverns, and other food- and beverage-serving businesses. All restaurant closures allowed restaurants to provide takeout options, though some counties restricted carryout alcohol. We could not comprehensively find that information so the data do not include alcohol restrictions. Also, we could not differentiate between reopening of indoor dining versus outdoor dining.

\section{Differences and Drivers of Local Policy}

Local orders affected large numbers of people across the country. Figure 1 shows places that had local-level variation in SIP orders that were in force in different weeks from their state's order. ${ }^{7}$ These include places where local orders took effect earlier than statewide orders, extended after statewide orders expired, and places with local orders in effect when the state never imposed a statewide order.

Table 2 presents some summary statistics for the 213 early-moving locations compared to all other counties. The early movers look quite different. They are much larger, with a mean population of about 315,000 versus 90,000 all other counties. ${ }^{8}$ Indeed, close to $20 \%$ of the U.S. population lives in these counties that moved independently of their state. Additionally, the early moving counties

\footnotetext{
7 Week definitions follow from Goolsbee and Syverson (2020) and were constructed to match the SafeGraph phone location data.

${ }^{8}$ County Population data from 2019 Census Bureau estimate.
} 
have an average population density more than double that of the other counties and a lower average voting share in 2016 for Donald Trump. ${ }^{9}$

The last two rows show the incidence of cases and deaths per million population for the early mover counties and for the non-early mover counties in the same state and in the first week that the county moved. We make this contemporaneous comparison deliberately. It is clear from the reported values in the table that the early moving counties had almost double the death rate and triple the case rate as other counties in the same state. However, because disease prevalence was trending upward over time and these counties moved before their respective states, a simple comparison of case rates at the times the later counties and states moved would make it look like early moving counties had lower infection rates at the time of implementation. That is merely a reflection of the differential timing, however.

The clear differences between early moving counties and other counties in their state is a caution for using state level data if some of the covariates of interest are correlated with (unmeasured) early adoption in the larger counties in that state.

\section{Local Policy vs. State Policy}

Most existing research on COVID policy has used state-level policy data, such as that reported in the New York Times (Lee et al., 2020). ${ }^{10}$ In Table 3, we document that local information contains important content for policy evaluation that state-level policy does not. The table reports results from regressions in Goolsbee and Syverson (2020) that evaluate the impact of shelter-inplace policies on the log number of consumer visits to the store in a given week using information

\footnotetext{
${ }^{9}$ Election data are from MIT Election Data + Science Lab (2018).

10 We found a small number of exceptions as described in footnote 2 above.
} 
on consumer visits from mobile phone location data collected by SafeGraph for more than 2.3 million businesses in 110 different industries.

We include store-level fixed effects and commuting-zone-by-week fixed effects in the regression. These fixed effects can control for the impact of local disease fear and help estimate the impact of policy alone. The regression compares places where the policy varies across a border within the same area. This includes variation from places like the Quad Cities metro area, where the Illinois towns of Moline and Rock Island had early sheltering orders, while Bettendorf and Davenport in Iowa never had sheltering orders. It also includes timing variation, like Waukegan, Illinois, which enacted a sheltering order in the week before Racine, Wisconsin did. Figure 2 shows the more than 500 counties where there is policy variation across borders during the sample. Goolsbee and Syverson (2020) show that not including these local controls can lead to estimated coefficients 10 times too large.

The regression also includes the number of deaths in the county (an inverse hyperbolic sine transformation to deal with the zeros), and two measures of policy. The first is just a state level measure of policy as used in most of the literature. The other modifies the state level-measure to also include the local policy information. All of the explanatory weight over economic activity loads on the local measure of policy, as expected. Controlling for that leaves the state-only policy with no additional explanatory content.

\section{Conclusion}

The local COVID-related policy variation embodied in this new data set affects $20 \%$ of the U.S. population, is correlated with observable characteristics of the places that adopt policies before their respective states, and contains substantially more information content than using the state level 
policy alone. We encourage anyone thinking about the impact of COVID policy in the pandemic to use this dataset. 


\section{Bibliography}

Alexander, Diane and Ezra Karger, 2020. "Do stay-at-home orders cause people to stay at home? Effects of stay-at-home orders on consumer behavior." FRB of Chicago Working Paper No. 2020-12. June 22.

Brzezinski, Adam, Guido Deiana, Valentin Kecht, and David Van Dijcke, 2020. "The COVID-19 Pandemic: Government vs. Community Action Across the United States." CEPR preprint in Covid Economics: Vetted and Real-Time Papers. April 20.

Gupta, Sumedha, Thuy D. Nguyen, Felipe Lozano Rojas, Shyam Raman, Byungkyu Lee, Ana Bento, Kosali I. Simon, and Coady Wing, 2020. "Tracking Public and Private Response to the COVID-19 Epidemic: Evidence from State and Local Government Actions." NBER Working Paper No. 27027.

Goolsbee, Austan and Chad Syverson. 2020. "Fear, Lockdown and Diversion: Comparing Drivers of Pandemic Economic Decline 2020.” NBER Working Paper 27432.

Lee, Jasmine C., Sarah Mervosh, Yuriria Avila, Barbara Harvey, and Alex Leeds Matthews. 2020. "See How all 50 States are Reopening (and Closing Again)." https://www.nytimes.com/interactive/2020/us/states-reopen-map-coronavirus.html, accessed July 31, 2020.

Swales, Vanessa, Patricia Mazzei, and Mike Baker "See Which States and Cities Have Told Residents to Stay Home." https://www.nytimes.com/interactive/2020/us/coronavirus-stay-at-homeorder.html, accessed April 18, 2020.

MIT Election Data + Science Lab, 2020. "County Presidential Election Returns 2000-2016." https://doi.org/10.7910/DVN/VOQCHQ, Harvard Dataverse, accessed August 8, 2020.

Raifman, Julia, Kristen Nocka, David Jones, Jacob Bor, Sarah Lipson, Jonathan Jay, and P. Chan, 2020. "COVID-19 US state policy database." Available at: www.tinyurl.com/statepolicies, accessed August 5, 2020 


\section{Table 1: Data Format}

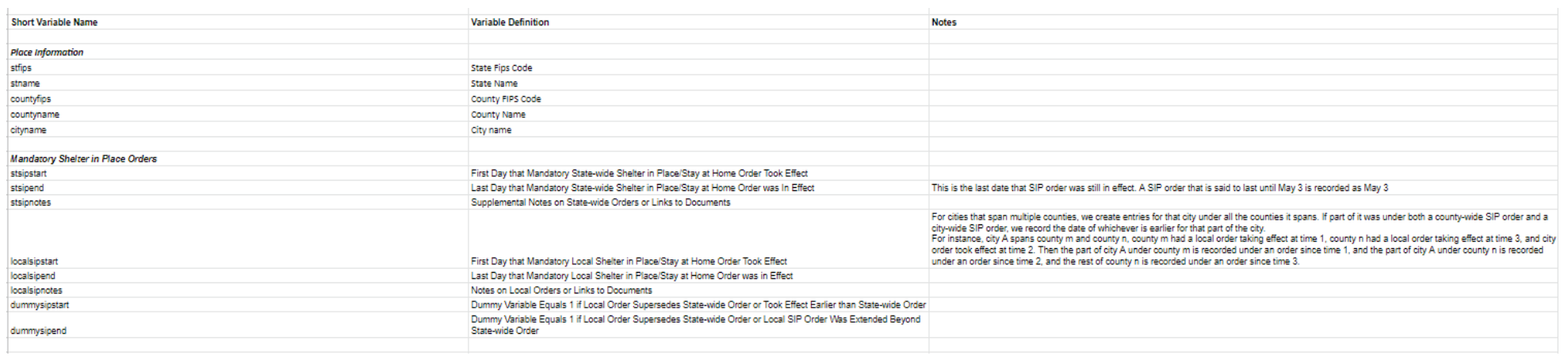

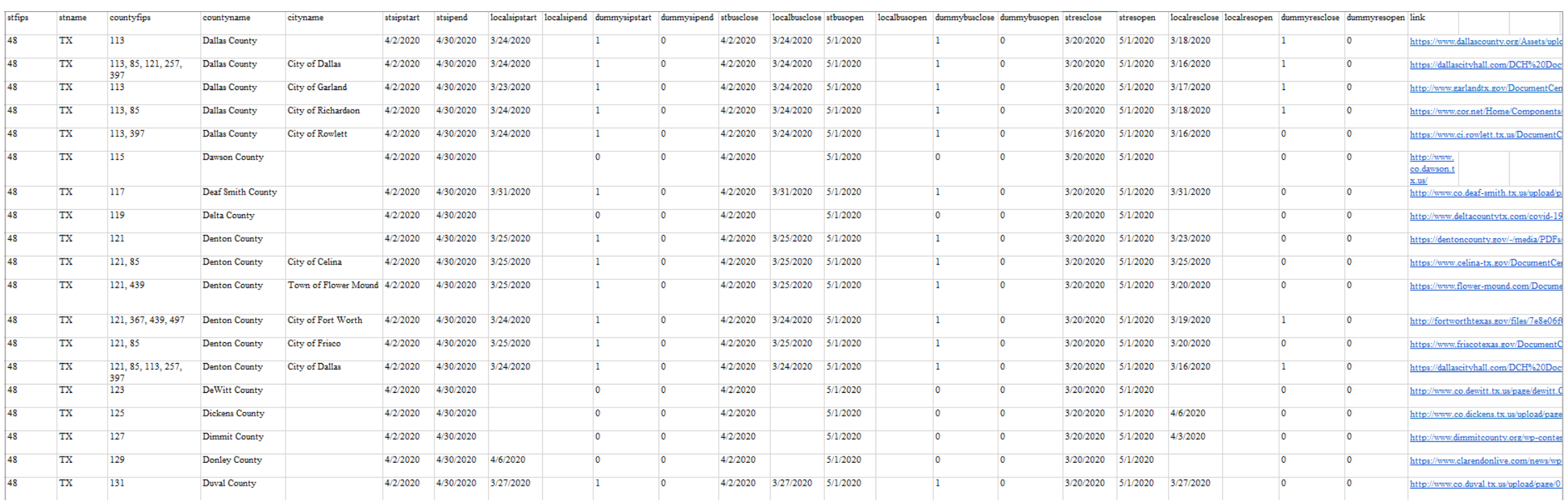


Table 2: Summary Statistics

\begin{tabular}{|c|c|c|}
\hline & $\begin{array}{c}\text { Local Order } \\
\text { Counties }\end{array}$ & $\begin{array}{c}\text { Non-local Order } \\
\text { Counties }\end{array}$ \\
\hline Number of Counties & 238 & 2895 \\
\hline Population & $\begin{array}{c}298,197 \\
(522,927)\end{array}$ & $\begin{array}{c}88,889 \\
(308,151)\end{array}$ \\
\hline Density (people per $\mathrm{mi}^{2}$ ) & $\begin{array}{c}460 \\
(939)\end{array}$ & $\begin{array}{c}208 \\
(1292)\end{array}$ \\
\hline Trump 2016 Vote Share & $\begin{array}{c}58.5 \% \\
(18.1 \%)\end{array}$ & $\begin{array}{c}63.6 \% \\
(15.4 \%)\end{array}$ \\
\hline Trump 2016 Vote Share (population weighted) & $44.2 \%$ & $46.2 \%$ \\
\hline COVID Cases per million population in the week SIP order took effect & $\begin{array}{c}213.5 \\
(371.5)\end{array}$ & $\begin{array}{c}62.3 \\
(184.7)\end{array}$ \\
\hline COVID Deaths per million population in the week SIP order took effect & $\begin{array}{c}4.3 \\
(16.8)\end{array}$ & $\begin{array}{c}2.3 \\
(3.1)\end{array}$ \\
\hline
\end{tabular}

Notes: The definition of early moving counties is aggregated to week level following the definitions in Goolsbee and Syverson (2020) to match SafeGraph weekly pattern data (Sunday-Saturday). This means that local orders that came before state orders but not by enough to be in separate weeks do not count as early movers in this table. Land area data comes from Census. Voting Share data excludes Alaska. Case and Death counts from New York Times Open Database, counts are cumulative counts at the end of each week (Saturday in SafeGraph weekly pattern) (accessed through https://github.com/nytimes/covid-19-data). We compute the COVID case rate and death rate for non-local order counties as of the week that the local order takes place but for all counties in that same state that had not yet put in an order (as described in the text). 
Table 3: Impact of Policy on $\ln ($ Consumer Visits)

\begin{tabular}{|c|c|c|}
\hline & $(1)$ & $(2)$ \\
\hline State or Local SIP Order in Effect & -0.077 & -0.074 \\
& $(0.012)$ & $(0.013)$ \\
State SIP Order in Effect & & 0.008 \\
& & $(0.021)$ \\
$\ln$ (County deaths) & -0.039 & -0.039 \\
{$[$ asinh transf] } & $(0.005)$ & $(0.005)$ \\
& & \\
$\mathrm{N}$ & $23,865,721$ & $23,865,721$ \\
$\mathrm{R}^{2}$ & 0.880 & 0.880 \\
FEs & Store & Store \\
& & C-Zone $\mathrm{x}$ Week \\
Weights: & C-Zone $\mathrm{x}$ Week & Visits in Jan \\
Cluster SE: & Cisits in Jan & County \\
& & \\
\hline
\end{tabular}

Notes: The dependent variable is log number of average consumer visits per day to the store. The SIP Order in Effect variables are indicators for shelter-in-place orders being in effect. One reflects if a local order is in effect or, in absence of any local order, whether a state-level order is in effect. The other indicator only reflects state-level orders. County deaths are the inverse hyperbolic sine transformation of the number of COVID deaths in the county. We use this transformation to account for the many zeros. Standard errors are clustered at the county level. 
Figure 1:

$20 \%$ of Population Live in Places with Local Orders

Starting/Ending Differently From State-Wide Orders By At Least 1 Week

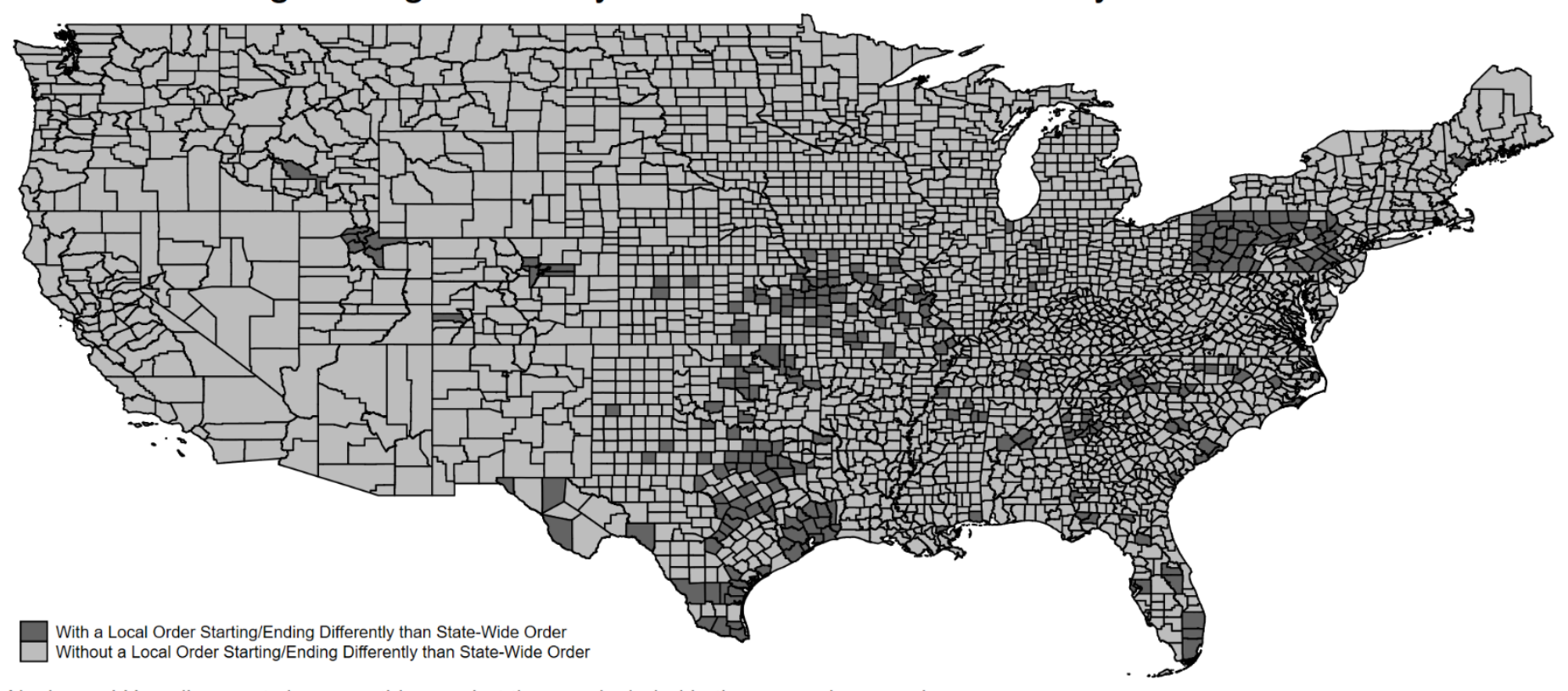

Alaska and Hawaii are not shown on this map but they are included in the regression sample.

Week definitions follow from Goolsbee and Syverson (2020) to match SafeGraph weekly pattern data. 
Figure 2:

Commuting Zones with Variation in Local Orders in Any Week

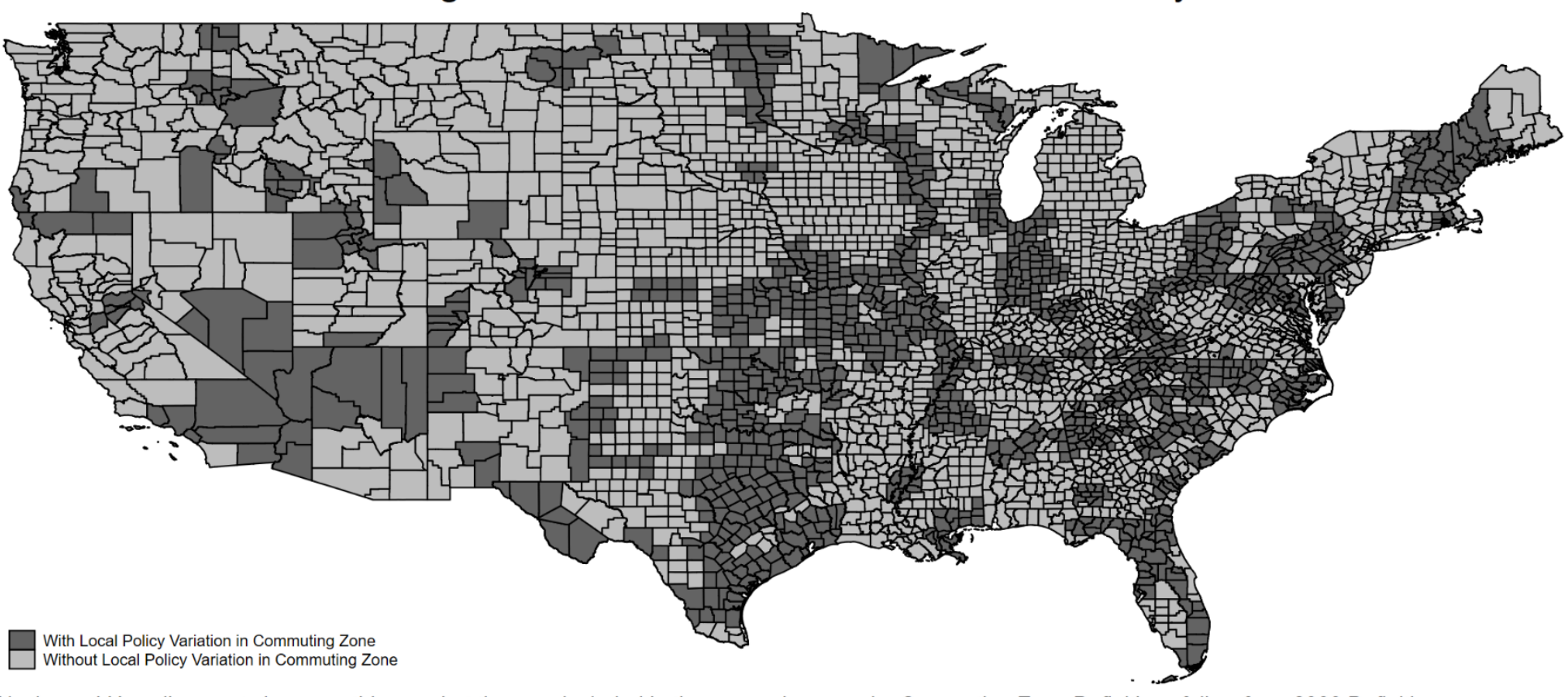

Alaska and Hawaii are not shown on this map but they are included in the regression sample. Commuting Zone Definitions follow from 2000 Definition. Week definitions follow from Goolsbee and Syverson (2020) to match SafeGraph weekly pattern. 